\title{
Children's Reward and Punishment Sensitivity Moderates the Association of Negative and Positive Parenting Behaviors in Child ADHD Symptoms
}

\author{
James J. Li \\ Department of Psychology, Waisman Center and University of Wisconsin - Madison, Madison, \\ WI, USA
}

\begin{abstract}
Atypical reward processing, including abnormal reward responsivity and sensitivity to punishment, has long been implicated in the etiology of ADHD. However, little is known about how these facets of behavior interact with positive (e.g., warmth, praise) and negative (e.g., hostility, harsh discipline) parenting behavior in the early expression of ADHD symptoms in young children. Understanding the interplay between children's reward processing and parenting may be crucial for identifying specific treatment targets in psychosocial interventions for ADHD, especially given that not all children benefit from contingency-based treatments (e.g., parent management training). The study consisted of a sample of kindergarten children $(N=201,55 \%$ male $)$ and their parents, who completed questionnaires about their parenting practices, their child's behaviors and participated in an observed parent-child play task in the laboratory. Children's reward responsivity and sensitivity to punishment were positively associated with child ADHD symptoms. However, children with high reward responsivity had more symptoms of ADHD but only under conditions of low negative parenting (self-reported and observed) and high self-reported positive parenting, compared to children with low reward responsivity. Children with high sensitivity to punishment had more ADHD symptoms relative to children with low sensitivity to punishment, but only under conditions in which observed praise was infrequent. Results provide evidence that individual differences in sensitivity to reward/punishment may be an important of marker of risk for ADHD, but also highlights how children's responses to positive and negative parenting behavior may vary by children's sensitivities. Clinical and treatment implications are discussed.
\end{abstract}

\section{Keywords}

ADHD; reward processing; parenting; parent-child relationships

\begin{abstract}
Attention-deficit/hyperactivity disorder (ADHD) is a childhood-onset disorder characterized by developmentally inappropriate levels of inattention, hyperactivity and impulsivity (American Psychiatric Association, 2013). ADHD is also one of the most prevalent disorders of childhood, affecting between $6-7 \%$ of children and adolescents worldwide
\end{abstract}

Correspondence: Please address all correspondence concerning this article to James J. Li, Department of Psychology, University of Wisconsin-Madison, 1202 West Johnson Street, Madison WI 53706. james.li@ wisc.edu. Tel: (608) $265-1091$.

Conflicts of Interest: The author declares no conflict of interest. 
(Willcutt, 2012). ADHD not only correlates with significant impairments in academic and social functioning, but also prospectively predicts substance use and criminality in later life (Langley et al., 2010). Psychosocial treatments that emphasize reinforcement contingencies are widely used to treat childhood symptoms of ADHD (e.g., parent training), but metaanalytic studies have shown that the positive effects of parent training treatments for ADHD range from null to strong (see review by Fabiano, Schatz, Aloe, Chacko, \& ChronisTuscano, 2015). Considering the enormous familial, economic, and societal impact of ADHD, more research is needed to better understand the complex interplay between the individual and environmental factors underlying its pathogenesis, as this may lead to the development of improved or novel treatments.

Atypical reward processing abilities have long been implicated in the etiology of ADHD (see review by Luman, Oosterlaan, \& Sergeant, 2005). One framework that may explain this association is reinforcement sensitivity theory (RST; Gray, 1970; Gray \& McNaughton, 2003; Corr, 2004). RST posits three systems that govern approach-avoidance behaviors: the behavioral activation system (BAS), which activates in response to positively valenced stimuli (i.e., rewards), the flight-fight-freeze system (FFFS), which activates in response to aversive stimuli, and the behavioral inhibition system (BIS), which resolves the approachavoidance conflict that arises when both BAS and FFFS are activated (Becker et al., 2013). The BIS has often been conceptualized as the sensitivity to punishment (SP) system, whereas the BAS has been conceptualized as the reward responsivity (RR) system (Becker et al., 2013). There have been several insightful reviews of the literature regarding RST constructs in relation to personality dimensions (Corr, 2004), substance use and eating disorders (Dawe \& Loxton, 2004), executive functions (Jackson et al., 2014) and ADHD (Becker et al., 2013; Luman et al., 2005). In particular, children with ADHD display a stronger proclivity towards smaller and more immediate rewards over larger, delayed ones (i.e., reward anticipation; Becker et al., 2013; Sonuga-Barke, Sergeant, Nigg, \& Willcutt, 2008). A recent meta-analysis showed that children with ADHD exhibit greater improvement in inhibitory control tasks when rewards are presented, suggesting that youths with ADHD have heightened RR compared to controls (Ma et al., 2014). This pattern of behavior is strongly suspected to reflect a dysfunction in the mesolimbic pathway of the brain (Plichta \& Scheres, 2014; Scheres, Milham, Knutson, \& Castellanos, 2007; Tripp \& Wickens, 2008).

In addition, children with ADHD may exhibit an atypical sensitivity to punishment or nonreward relative to typically-developing children (Quay, 1988). However, the direction of this association in the ADHD literature is unclear (see review by Luman, Tripp, and Scheres, 2010). For instance, some studies have shown reduced SP in children and adolescents with ADHD relative to controls during risk taking tasks (Groen, Gaastra, Lewis-Evans, \& Tucha, 2013). Humphreys and Lee (2013) demonstrated that children with ADHD displayed significantly less SP (in the form of an exploded balloon) during the balloon analogue risk task compared to controls. Researchers have posited that the reduced SP observed in children with ADHD may reflect a diminished ability to respond to performance feedback, as the over reactivity of the BAS may overrule the sympathetic response to the aversive stimuli (Newman \& Wallace, 1993). This reduced SP may lead to more risk-taking behaviors, particularly in children and adolescents (Groen et al., 2013). However, several 
studies have also found that children with ADHD are more sensitive to punishments than controls (Carlson, Mann, \& Alexander, 2000; Carlson \& Tamm, 2000; van Meel et al., 2005), such that the application of any type of contingency (reward or punishment) led to a significant increase in performance from baseline on cognitive tasks in children with ADHD. For instance, Furukawa and colleagues (2017) found that when compared to controls, children with ADHD displayed greater avoidance to a task that was four times more punishing than an alternative task, suggesting that children with ADHD experienced punishment as more aversive. Some researchers (e.g., Nigg \& Casey, 2005) have characterized this phenomenon as a problem of top-down prefrontal cortex regulation of the subcortical regions of the brain, which result in aberrant approach and avoidance behaviors.

There are several possible reasons why the extant literature on SP and ADHD has been inconsistent. First, few studies have accounted for the shared variance between children's RR and SP, despite consistent evidence that these systems co-activate in the mesolimbic reward circuitry (Luman et al., 2010). Becker and colleagues (2013) showed that the unique variance associated with RR (after accounting for individual differences in SP) was uniquely associated with ADHD symptoms and externalizing problems, whereas SP was uniquely associated with sluggish cognitive tempo and internalizing problems. Additionally, little is understood about the role of early environmental factors (e.g., parenting) and reward and punishment sensitivity in young children, and how their interaction may pertain to the development of ADHD. This gap in the literature is noteworthy, given the centrality of parental behavior on cognitive and behavioral development in children (Masten \& Coatsworth, 1998) and the consequences of negative parenting as they pertain to child ADHD (Deault, 2010).

Negative parenting is a reliable correlate of ADHD and externalizing behaviors in children (Burke, Pardini, \& Loeber, 2008; Kaiser, McBurnett, \& Pfiffner, 2011). Parents of children with ADHD are more harsh, critical and less physically involved with their children compared to parents of typically-developing children (Sonuga-Barke \& Halperin, 2010). However, the association between negative parenting and child externalizing behaviors more generally has been shown to be moderated by temperamental inflexibility (Sanson \& Prior, 1999), genetics (Li \& Lee, 2012; 2013), and fearfulness (Kiel \& Buss, 2011) in children. Erath and colleagues (2009) measured SP using skin conductance level reactivity (SCLR; where higher SCLR = greater SP) in a sample of 251 boys and girls (aged 8-9 years), and found that children with low SCLR had more externalizing problems relative to children with high SCLR, but only when these children experienced harsh negative parenting. In line with other behavioral findings (Groen, Gaastra, Lewis-Evans, \& Tucha, 2013; Humphreys \& Lee, 2013), this may suggest that for children with low SP, harsh and negative parenting may be especially ineffective given their under-arousal in the face of aversive consequences (Erath et al., 2009). This hypothesis has yet to be tested in the context of ADHD, however.

There has been much less research on the association of positive parenting behavior (e.g., positive reinforcement, involvement, warmth) and ADHD. High quality parenting is known to be inversely associated with ADHD (Keown, 2012; Richards et al., 2014). Although intervention studies have generally shown that improving parental behaviors (e.g., consistency, discipline, warmth) are associated with reductions in offspring ADHD 
symptoms (Chronis-Tuscano et al., 2011; Haack et al., 2017; Hinshaw, Owens, \& Wells, 2000; for an exception to these findings see Daley et al., 2014), not all children respond to intervention or positive parental behaviors similarly. Individual differences in children's sensitivity to reward may moderate the association between positive parental behavior and the development of ADHD. One emerging theory that may help to explain the role of sensitivity to reward as a moderator of parenting effects on child ADHD is differential susceptibility theory (Belsky \& Pluess, 2009), whereby certain characteristics of the child may confer increased risk for psychopathology in the presence of environmental adversity, but may simultaneously predict better than expected outcomes in the presence of environmental enrichment. For instance, a recent meta-analysis found that infants and children with difficult temperaments had worse behavioral outcomes given high levels of negative parenting, but also had fewer behavior problems when positive parenting was high relative to children with easy temperaments (Slagt et al., 2016). Extending this theory to reward processing and ADHD, one hypothesis that has yet to be tested is whether children who have heightened sensitivity to reward may be more likely to benefit (by virtue of having fewer ADHD symptoms) from positive parenting relative to children with lower sensitivity to reward. Furthermore, it is also plausible that these same children may also be more vulnerable (i.e., have more ADHD symptoms) to negative parenting, given that high RR has also been associated with poor impulse control (Franken \& Muris, 2006; Goudriaan, Oosterlaan, De Beurs, \& Van Den Brink, 2008), which may make it more difficult for these children to respond to harsh, critical, and inconsistent parenting.

This study used a rigorous multimethod approach to assess parenting behavior, including direct observations of parent behaviors during a parent-child play task and self-reported questionnaires. The first objective was to examine the association of RR and SP on child ADHD symptoms. In line with RST and ADHD, it was hypothesized that higher RR and lower SP would be associated with child ADHD symptoms, respectively. The second objective was to test the hypothesis that the association of parental behavior and child ADHD symptoms would be moderated by children's RR and SP. With respect to RR, it was hypothesized that positive parenting (e.g., warmth, involvement, praise and positive reinforcement) would be associated with fewer ADHD symptoms among children with high RR relative to children with low RR. Consistent with differential susceptibility hypothesis, negative parenting (e.g., harsh criticism, negativity) would be associated with more ADHD symptoms among children with high RR relative to children with low RR. With respect to SP, it was hypothesized that negative parenting (e.g., corporal punishment, observed negativity) would be associated with more ADHD symptoms among children with low SP, compared to children with high SP.

\section{Method}

\section{Participants and Procedures}

The current study is part of a longitudinal study on biological and environmental antecedents of trajectories of externalizing problems in children. The sample consisted of 201 parents and their kindergarten children (mean age $=6.04$, S.D. $=.40$ ), with and without early attention and behavioral problems. Participants were recruited through child development 
research registries, social media (i.e., Facebook posts, parenting blogs) and from brochures and flyers distributed in the community, including elementary schools, outpatient clinics, community centers and doctors' offices. Participants were ineligible to participate if they were previously diagnosed with an intellectual disability or Autism Spectrum Disorder, did not live with a biological parent at least half of the time, or were not fluent in English. Among child participants, $55.4 \%$ were male, $85.9 \%$ were Caucasian, and $20.7 \%$ met diagnostic criteria for any subtype of ADHD (4.9\% inattentive subtype, $9.8 \%$ hyperactive/ impulsive subtype, and $6.0 \%$ combined subtype) according to the Diagnostic Interview Schedule for Children, Version IV (DISC-IV; Shaffer, Fisher, Lucas, Dulcan, \& SchwabStone, 2000) administered by trained research staff to the child's biological parent during the lab visit. Importantly, this study was not an ADHD case-control designed sample, given the relatively young age of the participants. The DISC-IV was used for psychiatric diagnostic purposes, but self-report questionnaires provided by multiple informants were used to characterize ADHD dimensionally (i.e., symptom counts) rather than categorically (i.e., diagnoses) in the current study. Ninety-three percent of the parents who participated in the study were mothers, and $87.5 \%$ reported being married and living with a spouse. The sample was well-educated (84\% held at bachelor's degree) and had a high gross household income (median $=\$ 92,000$ ), which is representative of the surrounding community (i.e., urban city with a large public university). None of the children in the sample were reported to be on stimulant medications at the time of assessment. All study protocols were approved by the University of Wisconsin-Madison Education and Social Sciences Institutional Review Board (IRB\#2015-1177).

Eligible families were invited to the laboratory, where the child participant was asked to complete an IQ (abbreviated Wechsler Primary and Preschool Scale of Intelligence - Fourth Edition; WPPSI-IV) and executive function assessment (i.e., Executive Function (EF) Touch; http://eftouch.fpg.unc.edu/). The EF touch task consists of several computerized versions of child-friendly tasks for working memory (verbal and spatial), inhibitory control, and cognitive flexibility. These tasks were administered by a trained Ph.D. student in clinical or school psychology. To ensure standard administration, all assessments and scores were reviewed by a licensed clinical psychologist.

During the child assessment, a research assistant (undergraduate or post baccalaureate lab staff) administered the DISC-IV interview to the parent. The DISC-IV is a fully structured clinical interview, designed to be administered by laypersons as it is almost entirely comprised of closed-ended questions (i.e., yes/no) keyed to the Diagnostic and Statistical Manual of Mental Disorders (DSM). In addition, parents completed questionnaires of their parenting behaviors, their child's functioning across several domains (i.e., social, behavioral, emotional), and family history. At the conclusion of the assessment, the parent and child convened to take part in a parent-child interaction task that was video recorded (for additional details of this task, see Measures below).

\section{Measures}

Vanderbilt Assessment Scale (NICHQ, 2002).-Parents completed the Vanderbilt Assessment Scale, which consists of DSM criteria symptoms for ADHD, oppositional 
defiant disorder (ODD) and conduct disorder, and a brief set of screen items for anxiety and depressive disorders. Items were rated on a 4-point Likert-type scale, where parents were asked to rate on the frequency of their child's behaviors, where $0=$ rarely, $1=$ sometimes, 2 $=$ often and $3=$ very often, over the past 6 months. Per NICHQ (2002), items marked often or very often were scored as present (1), and items marked rarely or sometimes were scored as absent (0). All of the present ADHD symptoms (out of the 18 items) were summed to generate a total ADHD symptom score. In cases where both parents completed the measure $(n=39)$, the average of the sum score between both informants was used (the Pearson's correlation of parents' ratings was $=.58, p<.001$ ). The Vanderbilt Assessment Scale has shown convergence with results from a structured clinical interview conducted with parents in clinical and nonclinical samples of children (Wolraich, Lambert, Doffing et al., 2003). The scale had excellent internal consistency in the present sample (Cronbach's alpha $=.93$ ).

\section{Sensitivity to Punishment/Reward Responsivity Questionnaire for Children (SPSRQ-C; Colder \& Connor, 2004).-Parents completed a 33-item measure of their} child's sensitivity to punishment and rewards. Items were rated on a 5-point Likert scale, where $1=$ strongly disagree and $5=$ strongly agree. Two subscales were derived based on factor analytic studies of the SPSRQ-C (Colder et al., 2011; Luman et al., 2011). Sensitivity to punishment (SP) consisted of 15 items pertaining to fear/shyness (e.g., "your child often refrains from doing something because of fear of being embarrassed") and anxiety (e.g., "if your child thinks that something unpleasant is going to happen, they get pretty worked up"). Sensitivity to reward consisted of 18 items pertaining to reward responsivity (RR; e.g., "your child often does things to be praised"), drive (e.g., "your child likes to compete and do everything they can to win,") and impulsivity/fun-seeking (e.g., "your child engages in risky behavior for a quick reward"). To account for the potential overlap between drive and impulsivity/fun-seeking items and ADHD symptoms, the current study used only the items pertaining to $\mathrm{RR}^{1}$. In cases where both parents completed the measure $(n=39)$, the average of the sum score between informants was used (the Pearson's correlation of parents' ratings on $\mathrm{RR}=.22, p=.11$ and $\mathrm{SP}=.23, p=.15)$. Previous studies have demonstrated evidence of both external and convergent validity of the SPSRQ-C, as RR and SP scores were significantly associated with ADHD in a community sample of children ages 6-13 (Luman et al., 2012), and were significantly associated with laboratory measures of BIS/BAS in a sample of 9-12 year old American children (Colder \& O'Connor, 2004). The RR and the SP scales demonstrated excellent internal consistency in the current sample (Cronbach's alpha $=.85$ and .83 , respectively).

Alabama Parenting Questionnaire (APQ; Frick, 1991).-Parents self-reported on the frequency, where $1=$ never and $5=$ always, on 42 items related to their own parenting practices and behaviors. Global positive and negative dimensions of parenting behaviors have been delineated based on previous factor analytic studies (Frick \& Dantagnan, 2005; Kaiser, McBurnett, \& Pfiffner, 2011; Li \& Lee, 2012; Shelton, Frick, \& Wootton, 1996). The global positive dimension includes parents' level of involvement (e.g., "you help your child

\footnotetext{
${ }^{1}$ Analyses were also conducted using the full 18 item subscale for sensitivity to reward. Results were largely consistent with current analyses. Results available upon request.
} 
with his/her homework;" 10 items) and frequency of using positive reinforcement strategies (e.g., "you praise your child if he/she behaves well;" 6 items) with their child. The global negative dimension includes the parents' self-reported frequency of using corporal punishment (e.g., "you spank your child with your hand when he/she has done something wrong;" 10 items), having poor monitoring (e.g., "your child is at home without adult supervision;" 10 items) and being inconsistent in their discipline (e.g., "the punishment you give your child depends on your mood;" 6 items) with their child. A higher score on the global negative parenting dimension relates to more negative parenting behaviors, whereas a higher score on the global positive dimension relates to more positive parenting behaviors. In cases where both parents completed the measure $(n=39)$, the average of the score between informants was used (the Pearson's correlation of parents' ratings on positive parenting $=.14, p=.40$; negative parenting $=.27, p=.11$ ). Scores on the APQ have been shown to converge with observational measures of parents (Chronis-Tuscano et al., 2008; Hawes \& Dadds, 2006). Cronbach's alphas were .82 and .65 for the global positive parenting (16 items) and global negative parenting (26 items) dimensions for the present study, which is consistent with previous psychometric studies of the APQ (Shelton et al., 1996).

Dyadic Parent-Child Interaction Coding System (DPICS; Eyberg et al., 2013).Parents (usually the mother) and their children were asked to engage in three play-oriented conditions using toys strategically placed around an observation room. The three conditions consisted of 10 minutes of child-led play (i.e., the parent gives the child the choice to play with any toy in the room, and the parent is instructed to follow along according to the child's wishes), 10 minutes of parent-led play (i.e., the parent chooses which toy to play with, and the child must follow along according to the parent's wishes), and 5 minutes of cleanup time (i.e., the parent instructs the child to clean up the toys in the room without their assistance). Since the task was not observed live (it was video recorded), experimenters entered the room at each 5-minute interval to repeat the condition instructions to ensure the parent-child dyad was adherent to instructions of the condition. These interactions were video recorded with parental consent.

Observed instances of parental negativity and praise were coded using the DPICS (see Eyberg et al., 2013 for specific details on coding procedures). The DPICS is a rating system for parent and child behaviors observed during a parent-child interaction task that has previously demonstrated strong predictive validity and sensitivity to intervention effects (Thomas \& Zimmer-Gembeck, 2007). Coding was conducted by undergraduate research assistants and supervised by a Ph.D.-level research assistant with previous experience in DPICS coding. Coders participated in a full day of training, followed by several weeks of practice until 70\% inter-rater agreement was reached. After this threshold was reached, weekly coding team meetings were held to ensure reliability and accuracy. Multiple raters were responsible for coding a subset of videos. Twenty percent of videos were randomly selected and coded by a separate rater to estimate the percentage of agreement between raters. Observed negativity was coded whenever a parent "expressed disapproval of the child or the child's attributes, activities, products, or choices, and includes sarcastic, rude, critical, threatening or imprudent speech" (Eyberg et al., 2013, pp. 24). Examples include “you're 
being naughty," "that's not quite right, sweetie," or "what's with you today?" Observed praise was coded when a parent expressed a favorable judgment of an attribute, product, or behavior of the child. This study specifically focused on labeled (i.e., a positive evaluation of a specific behavior, activity or product of the child, e.g., "you did a great job building that tower") rather than unlabeled praise (i.e., unspecified evaluation of behavior, activity or product of the child, e.g., "great job"), the latter of which has been shown to either have no effect or even undermine cognitive and behavioral development in children (see Henderlong \& Lepper, 2002). Based on the recommendations described in Eyberg and colleagues (2013, pp. 250) and by previous studies (e.g., Chronis-Tuscano et al., 2008; Li \& Lee, 2012), the current study used percentage of observed negativity (negativity divided by total verbalizations during the entire task) and percentage of observed praise (labelled praise divided by total verbalizations during the entire task) as the independent variables. There were no significant differences in observed parental negativity and praise during either the child-led play ( $t=.29, p=.77$ and $t=.71, p=.48$, respectively) or the parent-led play conditions ( $t=-1.88, p=.07$ and $t=.18, p=.86$, respectively) when comparing the first five minutes and second five minutes of these conditions. DPICS variables have been previously shown to be associated with ADHD symptoms in a sample of children aged 6-9 (Li \& Lee, 2012) as well as with APQ variables in a sample of children aged 6-10 (Chronis-Tuscano et al., 2008). The inter-rater reliability (i.e., concordance between two independent coders for a random $20 \%$ of cases) for observed negativity and observed praise was $72 \%$ and $86 \%$, respectively.

\section{Data analysis}

Analyses were performed in Stata Version 14.2 (StataCorp, 2015). Hierarchical poisson regression models were fit to test the association of children's RR/punishment, negative/ positive dimensions of parenting, and their respective interactions on child ADHD symptoms. Poisson models were fit to account for count data (i.e., symptom counts of ADHD) and over-dispersion (i.e., variance > mean given the excess in zeros). The baseline model in the hierarchical poisson regression modeled the association between covariates and RR and SP (i.e., main effects) on ADHD symptoms. Four separate saturated models were fit on top of the baseline model, all of which included covariates (see section below), the main effects of RR/SP, and the interactions of global negative parenting (Model 1), observed negativity (Model 2), global positive parenting (Model 3), and observed praise (Model 4) with RR and SP, respectively, in predicting child ADHD symptoms. Significant interactions were probed using a median split of the moderator variable, per expert recommendations (Aiken \& West, 1991; Cohen, Cohen, West, \& Aiken, 2003). Model comparisons between the baseline and fully saturated models for each of the four models were performed using fitstat in Stata, which generates a McFadden's $R^{2}$ statistic. McFadden's $R^{2}$ provides an ordinary least squares (OLS) equivalent to the $R^{2}$ statistic and can be similarly interpreted as the proportion of total variability explained by the model (Long \& Freese, 2006). Power calculations for the regressions were performed using powerreg in Stata. The sample size ( $n$ $=201$ ) had $80 \%$ power to detect an $R^{2}$ effect of .30 (and $\Delta R^{2}$ of .05 from a full model to a reduced model) for four models, specifying 3 covariates, 3 main effects, and 2 interactions per model. 


\section{Covariates}

Child sex ( $n=110$ male), gross household income (dummy coded where $1=$ lowest quintile in the sample and $5=$ highest quintile; mean gross income $=\$ 102,000$, S.D. $=\$ 48,500$, range $=[10000,200000])$, and child ODD symptoms assessed from the parent-report of the Vanderbilt Assessment Scale (mean ODD symptoms $=.83$, S.D. $=1.69$, range $=[0,8]$ ) were included as covariates in each of the models. These covariates were included to account for the individual differences in reward processing based on child sex (Ding et al., 2017), socioeconomic status of the family (Hackman \& Farrah, 2009) and childhood aggression (Veroude et al., 2016).

\section{Results}

\section{Descriptive statistics and bivariate correlations}

Table 1 presents the means, standard deviations, and bivariate correlations of all primary study variables. Child ADHD symptoms were positively correlated with child RR ( $r=.22, p$ $<.01)$, global negative parenting $(r=.24, p<.01)$, and DPICS observed negativity $(r=.23, p$ $<.01)$. Child ADHD symptoms were also negatively correlated with APQ global positive parenting $(r=-.17, p<.05)$. RR was positively correlated with global negative parenting $(r$ $=.19, p<.05)$, although not with global positive parenting or observed negativity/praise. SP was not correlated with negative or positive dimensions of parenting assessed globally or observationally.

\section{Baseline model: Association of RR and SP on child ADHD symptoms}

Table 2 presents the association between RR and SP for child ADHD symptoms, controlling for child sex, household income, and child ODD symptoms (i.e., main effects model). RR and SP were positively associated with child ADHD symptoms $(b=.078$, s.e. $=.014, p$ $<.001$ and $b=.016$, s.e. $=.006, p<.01$, respectively). Including the effects of covariates, this model accounted for $24.1 \%$ of the total variance in child ADHD symptoms.

\section{Models 1 and 2: Global and observed negative parenting, RR and SP, and their interactions on child ADHD symptoms}

Model 1 examined the interactive effects of global negative of parenting with RR and SP (i.e., RR x negative parenting, SP x negative parenting) on child ADHD symptoms, controlling for child sex, household income, and child ODD symptoms (Table 3).

Accounting for covariates and RR and SP, global negative parenting was associated with child ADHD symptoms $(b=.025$, s.e. $=.011, p=.032$ ), explaining $24.3 \%$ of the total variance in ADHD symptoms, resulting in an $\Delta R^{2}$ of .002 from the baseline model. No interaction between global negative parenting and SP was detected $(b=-.002$, s.e. $=.001, p$ $=.109)$. However, the interaction between RR and global negative parenting was significant $(b=-.009$, s.e. $=.004, p=.011)$. A post hoc margins test of the interaction revealed that significant differences between the high (i.e., above the median) and low (below the median) RR groups were only observed at the low end of the global negative parenting spectrum (see regions with non-overlapping 95\% confidence intervals in Figure 1). When global negative parenting was high however, no group differences were observed, indicating that children 
with higher RR had overall higher levels of ADHD when global negative parenting was low relative to children with low RR. The interaction model explained $25 \%$ of the variance in child ADHD symptoms ( $\Delta R^{2}$ of .009 from the baseline model).

Model 2 tested the interaction of observed negativity with RR and SP (i.e., RR x observed negativity, SP x observed negativity) on child ADHD symptoms, controlling for child sex, household income, and child ODD symptoms. Results paralleled the findings from Model 1. A significant main effect of observed negativity and child ADHD symptoms was detected ( $b$ $=2.492$, s.e. $=1.046, p=.017$ ), as this model explained $25.2 \%$ of the variance for child ADHD symptoms. No significant interaction between observed negativity and SP was detected $(b=-.171$, s.e. $=.183, p=.351)$, but there was a significant interaction between observed negativity and RR $(b=-1.220$, s.e. $=.370, p=.001)$. Consistent with Model 1 , significant group differences between the high versus low RR groups were only observed when negativity was less frequently used by the parent (i.e., $6 \%$ or fewer of total verbalizations), whereby children high on RR had overall more ADHD symptoms compared to children low on RR. When negativity was high, no group differences were observed (see Figure 2). The interaction model explained $26.2 \%$ of the total variance in child ADHD symptoms ( $\Delta R^{2}$ of .021 from the baseline model).

\section{Models 3 and 4: Global and observed positive parenting, RR and SP, and their interactions on child ADHD symptoms}

Model 3 examined the interactive effects of global positive of parenting with RR and SP on child ADHD symptoms, controlling for child sex, household income, and child ODD symptoms. Global positive parenting was inversely associated with child ADHD symptoms ( $b=-.039$, s.e. $=.008, p<.001)$. This model explained $26 \%$ of the total variance in ADHD symptoms, resulting in an $\Delta R^{2}$ of .019 from the baseline model. No interaction between global positive parenting and SP was detected $(b=.001$, s.e. $=.001, p=.538)$. However, the interaction between RR and global positive parenting was significant $(b=.008$, s.e. $=.003, p$ $=.007)$. A post hoc margins test of the interaction revealed that significant differences between the high (i.e., above the median) and low (below the median) RR groups were only observed at the high end (i.e., mean APQ positive parenting score > 65) of the spectrum, whereby children with high RR had significantly higher levels of ADHD symptoms relative to children with low RR (see Figure 3); no group differences were observed at low levels of global positive parenting. The interaction model explained $26.6 \%$ of the variance in child ADHD symptoms ( $\Delta R^{2}$ of .025 from the baseline model).

Finally, Model 4 examined the interactive effects of observed praise with RR and SP on child ADHD symptoms, controlling for child sex, household income, and child ODD symptoms. No association was detected between observed praise and child ADHD symptoms $(b=.415$, s.e. $=1.434, p=.772)$. The addition of observed praise into the baseline model explained $24.7 \%$ of the total variance in $\operatorname{ADHD}\left(\Delta R^{2}\right.$ of .006 from the baseline model). The interaction of observed praise and RR was not significant ( $b=-.621$, s.e. $=.437, p=.155)$, but a significant interaction between observed praise and SP was detected $(b=-.962$, s.e. $=.212, p<.001)$. Post hoc test of the interaction revealed that significant differences between the high (i.e., above the median) and low (below the median) 
SP were only observed when instances of observed praise were infrequent $(<4 \%$ of total verbalizations), whereby children with high SP had significantly higher levels of ADHD symptoms relative to children with low SP (see Figure 4); no group differences were observed when parents were observed to praise frequently (i.e., $>4 \%$ of total verbalizations). The interaction model explained $26.6 \%$ of the variance in child ADHD symptoms $\left(\Delta R^{2}\right.$ of .025 from the baseline model).

\section{Discussion}

The current study examined the association of children's RR and SP and their ADHD symptoms using a well-characterized sample of kindergarten children. Additionally, children's RR and SP were examined as moderators in the association between negative and positive parenting behavior, which were self-reported and observed in the laboratory, on child ADHD symptoms.

Consistent with previous studies (Becker et al., 2013; Wilbertz et al., 2012; Sonuga-Barke et al., 2008; Tripp \& Alsop, 2001), children's RR was positively associated ADHD with symptoms. This extends the extant literature on heightened RR and ADHD to a younger population of children (i.e., kindergarteners) and reinforces the view that dysfunction in BAS may be a neurobiological marker for ADHD. However, children's SP was also positively associated with ADHD symptoms, which was contrary to what was expected. Children with ADHD are also known to exhibit poor affect regulation (Nigg, Goldsmith, \& Sachek, 2004), which may disrupt their ability to properly adapt to and learn from aversive feedback. The current findings were robust given that the covariation between RR and SP was accounted for in the models, in addition to the potential confounding effects of sex, income, and child ODD symptoms. Previous studies have indicated these factors may have contributed to the inconsistent findings in the field with respect to SP and ADHD (Becker et al., 2013; Humphreys \& Lee, 2011). Nonetheless, the results need to be replicated before stronger inferences can be made with respect to the strength of the association of SP and ADHD.

Negative dimensions of parenting were moderated by children's RR in relation to ADHD symptoms, such that high RR was associated with more ADHD symptoms when global negative parenting was low compared to children with low RR. The same direction of effect was observed with respect to observed parental negativity, as high RR was associated with more ADHD symptoms relative to children with low RR when observed parental negativity was infrequent, but not when negativity was high. No differences between children with high and low RR emerged when global negative parenting and observed negativity was high, however. The results add to a growing body of literature regarding how certain characteristics (e.g., RR, genes, temperament) may lead to individual differences in how children respond to parenting (Erath et al., 2009; Kiel \& Buss, 2011; Li \& Lee, 2012; 2013; Sanson \& Prior, 1999). It is important to note that low negative parenting is not necessarily equivalent to high positive parenting (Kaiser et al., 2011; Li \& Lee, 2011; Pettit et al., 1997). Future studies should examine more extreme variations in negative parenting (e.g., maltreatment) or conduct experimental studies (e.g., randomized controlled trial), as it is possible that the differential susceptibility effects of children's RR may be observed under 
more extreme environmental conditions, but not under mild or less activating ones $(\mathrm{Li}$, 2017).

Indeed, when positive dimensions of parenting were also examined, high RR was associated with more ADHD symptoms under conditions of high global positive parenting (but not observed praise) relative to children with low RR. In other words, there was no promotive association of global positive parenting (i.e., warmth, involvement) on child ADHD symptoms among children with high RR. These findings were contrary to the hypothesis that children with high RR would be differentially susceptible to both positive and negative parenting. That is, children with high RR did not exhibit more symptoms of ADHD under conditions of environmental adversity (i.e., high negative parenting and low positive parenting) nor did they exhibit fewer symptoms of ADHD under conditions of environmental enrichment (i.e., low negative talk, low global negative parenting and high global positive parenting) relative to children with low RR. One plausible explanation is that heightened RR may disrupt how children respond to naturalistic positive cues from their parents, particularly when these cues are inconsistent or are unassociated with child behavior. Another possibility is that the rewarding aspects of global parental behavior may not have been sufficiently assayed. Indeed, when positive parental behavior was measured from the observed frequency of praise during a structured parent-child play task, children with high RR were just as likely to benefit from parents' frequent use of relative to children with low RR (i.e., no between group differences on ADHD symptoms). Thus, providing sincere and highly specific praise of the child may be especially crucial for children with dysfunctional reward processing systems (Hederlong \& Lepper, 2002), as children with high RR may respond more favorably to only certain aspects of positive parental behavior (e.g., salience, rather than just the frequency of reward).

Contrary to the original hypothesis, SP was observed to moderate the association of observed praise and child ADHD symptoms such that compared to low SP, high SP was associated with more ADHD symptoms when parents praised their children less frequently. At high levels of parental praise, no differences in ADHD symptoms between groups were found. Because the BIS is not only sensitive to signals of punishment, but also to non-reward (Dadds \& Salmon, 2003), one possible explanation for these findings is that children with high SP may struggle to behave when there is inconsistency or a general lack of verbal reinforcement by their parents. Furthermore, high SP/BIS has also been shown to be associated with anxiety (Torrubia, Avila, Molto, \& Caseras, 2001), and co-occurring child anxiety may potentially moderate the positive effects of parental praise as it pertains to behavior (see meta-analysis by McLeod, Wood, \& Weisz, 2007). These findings should be interpreted with caution however, given that this interaction was not replicated by the global positive parenting measure and that child anxiety symptoms were not assessed in the current analysis.

Finally, SP did not moderate the association of observed or self-reported negative parenting in relation to child ADHD symptoms. It is important to note (as other have, see Humphreys and Lee, 2011) that positive punishment (whereby an aversive stimulus is applied, e.g., corporal punishment, criticism) has different effects on child behavior than negative punishment (removal of a positive stimulus, taking away privileges, time-out). Studies that 
use experimental of paradigms to measure SP (e.g., skin conductance reactivity levels or heart rate in response to stress tasks; Erath et al., 2009; Crone et al., 2003) may not be comparable to questionnaire studies of SP given the ethical concerns over administering positive punishments to children in the context of a research study. Thus, different experimental paradigms used to measure sensitivity to punishment may lead to inconsistent findings as they relate to ADHD, given that children will likely respond differently to qualitatively different (i.e., positive versus negative) punishment conditions. This distinction may be especially important in brain imaging studies, as the activation of brain regions involved in reward processing differ in the response to aversive stimuli compared to a decrease, delay or removal of positive stimuli (Luman et al., 2010). Additionally, it is possible that children's SP may not have been affected by the types of parental behavior that were assayed in the present study, such that more extreme aspects of parental behavior (e.g., maltreatment, post- parent-training treatment effects) may be necessary to activate the BIS/BAS response. Combined with the equivocal findings in the literature with respect to the association between SP and ADHD, the null results should be interpreted cautiously until they have been replicated.

Several limitations should be noted. First, measures of ADHD were limited to parent reports. Furthermore, the inter-rater reliability of the DISC interview could not be established given that it was not audio-recorded. Considering the importance of multi-informant designs in the study of child ADHD, replication of the findings is strongly warranted. Second, although a multimethod approach was used to assess parenting behavior (i.e., questionnaire and observations), only the parent-report was used to assess children's RR and SP. In the cases where both maternal and paternal measures were available, no significant correlations between raters on child RR and SP. There is relatively little research on informant agreement on child RR/SP (for a very recent investigation of parent-child agreement on BIS/BAS measures however, see De Decker et al., 2017). This may have led to confounds due to shared method variance. Future studies should measure children's RR and SP using multiple approaches, such as psychophysiological (e.g., skin conductance), neuroimaging (e.g., fMRI), and behavioral paradigms (e.g., monetary incentive delay or risk tasking tasks). For instance, longitudinal studies that employ multiple methodological approaches for reward processing can test the causal models of risk for ADHD. Replication of these effects using multiple paradigms may provide the basis for further research. Third, this investigation only focused on the parental main effects on child ADHD, even though parent-child dynamics are known to be transactional (Theule et al., 2013) such that children with ADHD may potentially elicit more negative (and less positive) parenting as well. Future studies should also consider using multiple assessment methods for parent-child dynamics (see $\mathrm{Li}$, in press for a recent example of combining mobile technology and observational measures to assay parent-child dynamics). Fourth, ADHD is heterogeneous with a complex etiology. Hence, while the models explained about a quarter of the variance in ADHD symptoms, the individual variables themselves explained only a small fraction of that amount. Fifth, the sample was predominantly Caucasian and of high income status, which was representative of the surrounding community but unrepresentative of the general population. Thus, the current results may lack generalizability and should be replicated in more diverse populations. Sixth, the cross-sectional nature of the study precluded the ability to make 
inferences about how RR and punishment scale with ADHD symptoms over time.

Longitudinal studies are needed to understand whether reward processing constitutes a developmentally-sensitive marker of ADHD. And seventh, parents may have been motivated to self-report their parenting behaviors in a socially desirable way and under report on their negative parenting. However, this concern was somewhat mitigated by the concordance between the APQ and DPICS negative parenting variables.

The findings may have potential clinical implications, particularly with respect to assessment and treatment decisions for children with ADHD. Individual differences in children's RR may partially explain why behaviorally-based (e.g., parenting management training) treatments do not confer beneficial effects for all children (Fabiano et al., 2015), as children with high RR had generally high ADHD symptoms even when positive parenting was high and negative parenting was low. The combination of medications and behaviorallybased (e.g., parent training) interventions for ADHD may be especially beneficial for the subset children with both high RR and ADHD, given that methylphenidates have been shown to normalize motivation and response to rewards in children with ADHD relative to non-ADHD controls (Rubia et al., 2009) and may potentially unlock the beneficial effects of behavioral treatments for these children. The findings may also suggest that children with low RR may be more likely to benefit from established psychosocial treatments such as parent training, even in the absence of medication. Future clinical studies of ADHD should strongly consider assessing reward processing, as this information may lead to more refined diagnostic techniques in assessment and more precise treatments for children and families with ADHD.

To conclude, these results provide further evidence that atypical reward processing may be an important of marker of risk for ADHD, but it also highlights how children's responses to positive and negative parenting behavior may vary by children's reward and punishment sensitivity. These constructs may be an important marker in diagnostic predictions of ADHD, adding to the prospect of tailoring treatments to optimally benefit the individual (Collin \& Varmus, 2015).

\section{Funding and Acknowledgements:}

The author was supported in part by a core grant to the Waisman Center from the National Institute of Child Health and Human Development (U54HD090256) and from the Wisconsin Alumni Research Foundation. The author expresses deep gratitude to all the families that participated in the study, and to Emily Hilton and Sara Jeglum who assisted the author with portions of the analyses and proofreading of the final version of the manuscript.

\section{References}

Aiken LS, \& West SG. (1991). Multiple regression: Testing and interpreting interactions. Thousand Oaks, CA: SAGE Publications, Inc.

American Psychiatric Association. (2013). Diagnostic and Statistical Manual of Mental Disorders (5th ed.). Washington, DC: Author.

Alsop B, Furukawa E, Sowerby P, Jensen S, Moffat C, \& Tripp G. (2016). Behavioral sensitivity to changing reinforcement contingencies in attention-deficit hyperactivity disorder. The Journal of Child Psychology and Psychiatry, 57, 947-956. Doi: 10.1111/jcpp.12561 [PubMed: 27079299]

Becker SP, Fite PJ, Garner AA, Greening L, Stoppelbein L, \& Luebbe AM. (2013). Reward and punishment sensitivity are differentially associated with ADHD and sluggish cognitive tempo 
symptoms in children. Journal of Research in Personality, 47, 719-727. Doi: 10.1016/ j.jrp.2013.07.001

Belsky J, \& Pluess M. (2009). Beyond diathesis stress: Differential susceptibility to environmental influences. Psychological Bulletin, 135, 885-908. Doi: 10.1037/a0017376 [PubMed: 19883141]

Burke JD, Pardini DA, \& Loeber R. (2008). Reciprocal relationships between parenting behavior and disruptive psychopathology from childhood through adolescence. Journal of Abnormal Child Psychology, 36, 679-692. Doi: 10.1007/s10802-008-9219-7 [PubMed: 18286366]

Carlson CL, \& Tamm L. (2000). Responsiveness of children with attention deficit-hyperactivity disorder to reward and response cost: Differential impact on performance and motivation. Journal of Consulting and Clinical Psychology, 68, 73-83. Doi: 10.1037/0022-006X.68.1.73 [PubMed: 10710842]

Carlson CL, Mann M, \& Alexander DK. (2000). Effects of reward and response cost on the performance and motivation of children with ADHD. Cognitive Therapy and Research, 24, 87-98. Doi: 10.1023/A:1005455009154

Chronis-Tuscano A, Raggi VL, Clarke TL, Rooney ME, Diaz Y, \& Pian J. (2008). Associations between maternal attention-deficit/hyperactivity disorder symptoms and parenting. Journal of Abnormal Child Psychology, 36, 1237 Doi: 10.1007/s10802-008-9246-4 [PubMed: 18553132]

Chronis-Tuscano A, O’Brien KA, Johnston C, Jones HA, Clarke TL, Raggi VL, ... \& Seymour KE. (2011). The relation between maternal ADHD symptoms \& improvement in child behavior following brief behavioral parent training is mediated by change in negative parenting. Journal of Abnormal Child Psychology, 39, 1047-1057. Doi: 10.1007/s10802-011-9518-2 [PubMed: 21537894]

Cohen J, Cohen P, West SG, \& Aiken LS. (2003). Applied multiple regression/correlation analysis for the behavioral sciences (3rd ed.). Mahwah, NJ: Lawrence Erlbaum Associates, Inc.

Colder CR, \& O'connor RM. (2004). Gray's reinforcement sensitivity model and child psychopathology: Laboratory and questionnaire assessment of the BAS and BIS. Journal of Abnormal Child Psychology, 32, 435-451. Doi: 10.1023/B:JACP.0000030296.54122.b6 [PubMed: 15305548]

Corr PJ. (2004). Reinforcement sensitivity theory and personality. Neuroscience \& Biobehavioral Reviews, 28, 317-332. Doi: 10.1016/j.neubiorev.2004.01.005 [PubMed: 15225974]

Crone EA, Richard Jennings J, \& Van Der Molen MW. (2003). Sensitivity to interference and response contingencies in Attention-Deficit/Hyperactivity Disorder. Journal of Child Psychology and Psychiatry, 44, 214-226. Doi: 10.1111/1469-7610.00115 [PubMed: 12587858]

Dadds MR, \& Salmon K. (2003). Punishment insensitivity and parenting: Temperament and learning as interacting risks for antisocial behavior. Clinical Child and Family Psychology Review, 6, 6986. Doi: 10.1023/A:1023762009877 [PubMed: 12836578]

Daley D, Van der Oord S, Ferrin M, Danckaerts M, Doepfner M, Cortese S, \& Sonuga-Barke EJ. (2014). Behavioral interventions in attention-deficit/hyperactivity disorder: a meta-analysis of randomized controlled trials across multiple outcome domains. Journal of the American Academy of Child \& Adolescent Psychiatry, 53, 835-847. Doi: 10.1016/j.jaac.2014.05.013 [PubMed: 25062591]

Dawe S, \& Loxton NJ. (2004). The role of impulsivity in the development of substance use and eating disorders. Neuroscience \& Biobehavioral Reviews, 28, 343-351. Doi: 10.1016/ j.neubiorev.2004.03.007 [PubMed: 15225976]

Deault LC. (2010). A systematic review of parenting in relation to the development of comorbidities and functional impairments in children with attention-deficit/hyperactivity disorder (ADHD). Child Psychiatry \& Human Development, 41, 168-192. Doi: 10.1007/s10578-009-0159-4 [PubMed: 19768532]

De Decker A, Verbeken S, Sioen I, Michels N, Vervoort L, Braet C, \& De Henauw S. (2017). BIS/BAS Scale in primary school children: Parent-child agreement and longitudinal stability. Behaviour Change, 34, 98-116. Doi: 10.1017/bec.2017.8

De Los Reyes A, Thomas SA, Goodman KL, \& Kundey SMA. (2013). Principles underlying the use of multiple informants' reports. Annual Review of Clinical Psychology, 9, 123-149. 
Ding Y, Wang E, Zou Y, Song Y, Xiao X, Huang W, \& Li Y. (2017). Gender differences in reward and punishment for monetary and social feedback in children: An ERP study. PLoS ONE, 12, e0174100 Doi: 10.1371/journal.pone.0174100 [PubMed: 28346515]

Erath SA, El-Sheikh M, \& Mark Cummings E. (2009). Harsh parenting and child externalizing behavior: Skin conductance level reactivity as a moderator. Child Development, 80, 578-592. Doi: 10.1111/j.1467-8624.2009.01280.x [PubMed: 19467012]

Eyberg SM, Nelson MM, Ginn NC, Bhuiyan N, \& Boggs SR. (2013). Dyadic-Parent-Child Interaction Coding System: Comprehensive Manual for Research and Training (4th ed). Gainesville, FL: PCIT International Retrieved from http://www.pcit.org/measures.html.

Fabiano GA, Schatz NK, Aloe AM, Chacko A, \& Chronis-Tuscano A. (2015). A systematic review of meta-analyses of psychosocial treatment for attention-deficit/hyperactivity disorder. Clinical Child and Family Psychology Review, 18, 77-97. Doi: 10.1007/s10567-015-0178-6 [PubMed: 25691358]

Franken IH, \& Muris P. (2006). Gray's impulsivity dimension: A distinction between reward sensitivity versus rash impulsiveness. Personality and Individual Differences, 40, 1337-1347. Doi. 10.1016/j.paid.2005.11.016

Frick PJ. (1991). The Alabama parenting questionnaire. Unpublished rating scale, University of Alabama. Retrieved from https://cyfar.org/alabama-parenting-questionnaire.

Frick PJ, \& Dantagnan AL. (2005). Predicting the stability of conduct problems in children with and without callous-unemotional traits. Journal of Child and Family Studies, 14, 469-485. Doi: 10.1007/s10826-005-7183-1

Furukawa E, Alsop B, Sowerby P, Jensen S, \& Tripp G. (2017). Evidence for increased behavior control by punishment in children with attention-deficit hyperactivity disorder. The Journal of Child Psychology and Psychiatry, 58, 248-257. Doi: 10.1111/jcpp.12635 [PubMed: 27611786]

Geurts HM, Van der Oord S, \& Crone EA. (2006). Hot and cool aspects of cognitive control in children with ADHD: decision-making and inhibition. Journal of Abnormal Child Psychology, 34, 811-822. Doi: 10.1007/s10802-006-9059-2

Goudriaan AE, Oosterlaan JAAP, De Beurs EDWI, \& Van Den Brink W. (2008). The role of selfreported impulsivity and reward sensitivity versus neurocognitive measures of disinhibition and decision-making in the prediction of relapse in pathological gamblers. Psychological Medicine, 38, 41-50. Doi: 10.1017/S0033291707000694 [PubMed: 17498322]

Gray JA. (1970). The psychophysiological basis of introversion-extraversion. Behaviour Research and Therapy, 8, 249-266. Doi: 10.1016/0005-7967(70)90069-0 [PubMed: 5470377]

Gray JA, \& McNaughton N. (2003). The neuropsychology of anxiety: An enquiry into the function of the septo-hippocampal system (No. 33). Oxford university press.

Groen Y, Gaastra GF, Lewis-Evans B, \& Tucha O. (2013). Risky behavior in gambling tasks in individuals with ADHD - a systematic literature review. PLoS ONE, 8, 1-16. Doi: 10.1371/ journal.pone.0074909

Haack L, Villodas M, McBurnett K, Hinshaw S, \& Pfiffner LJ. (2017). Parenting as a mechanism of change in psychosocial treatment for youth with ADHD, Predominantly Inattentive Presentation. Journal of Abnormal Child Psychology, 45, 841-855. Doi: 10.1007/s10802-016-0199-8 [PubMed: 27628742]

Hackman DA, \& Farah MJ. (2009). Socioeconomic status and the developing brain. Trends in Cognitive Sciences, 13, 65-73. Doi: 10.1016/j.tics.2008.11.003 [PubMed: 19135405]

Hawes DJ, \& Dadds MR. (2006). Assessing parenting practices through parent-report and direct observation during parent-training. Journal of Child and Family Studies, 15(5), 554-567. Doi: 10.1007/s10826-006-9029-x

Henderlong J, \& Lepper MR. (2002). The effects of praise on children's intrinsic motivation: a review and synthesis. Psychological Bulletin, 128, 774-795. Doi: 10.1037/0033-2909.128.5.774 [PubMed: 12206194]

Heym N, Kantini E, Checkley HLR, \& Cassaday HJ. (2015). Gray's revised reinforcement sensitivity theory in relation to attention-deficit/hyperactivity and Tourette-like behaviors in the general population. Personality and Individual Differences, 78, 24-28. Doi: 10.1016/j.paid.2015.01.012 
Hinshaw S, Owens E, \& Wells K. (2000). Family processes and treatment outcome in the MTA: Negative/ineffective parenting practices in relation to multimodal treatment. Journal of Abnormal Child Psychology, 28, 555-568. Doi: 10.1023/A:1005183115230 [PubMed: 11104317]

Humphreys KL, \& Lee SS. (2011). Risk taking and sensitivity to punishment in children with ADHD, ODD, ADHD+ ODD, and controls. Journal of Psychopathology and Behavioral Assessment, 33, 299-307. Doi: 10.1007/s10862-011-9237-6

Jackson CJ, Loxton NJ, Harnett P, Ciarrochi J, \& Gullo MJ. (2014). Original and revised reinforcement sensitivity theory in the prediction of executive functioning: A test of relationships between dual systems. Personality and Individual Differences, 56, 83-88. Doi: 10.1016/j.paid.2013.08.024

Kaiser NM, McBurnett K, \& Pfiffner LJ. (2011). Child ADHD severity and positive and negative parenting as predictors of child social functioning: Evaluation of three theoretical models. Journal of Attention Disorders, 15, 193-203. Doi: 10.1177/1087054709356171 [PubMed: 20424006]

Keown LJ. (2012). Predictors of boys' ADHD symptoms from early to middle childhood: The role of father-child and mother-child interactions. Journal of Abnormal Child Psychology, 40, 569-581. Doi: 10.1007/s10802-011-9586-3 [PubMed: 22038253]

Kiel EJ, \& Buss KA. (2011). Prospective relations among fearful temperament, protective parenting, and social withdrawal: The role of maternal accuracy in a moderated mediation framework. Journal of Abnormal Child Psychology, 39, 953-966. Doi: 10.1007/s10802-011-9516-4 [PubMed: 21537895]

Langley K, Fowler T, Ford T, Thapar AK, Van Den Bree M, Harold G, ... \& Thapar, A. (2010). Adolescent clinical outcomes for young people with attention-deficit hyperactivity disorder. The British Journal of Psychiatry, 196, 235-240. Doi: 10.1192/bjp.bp.109.066274 [PubMed: 20194547]

Li JJ, \& Lee SS. (2012). Association of positive and negative parenting behavior with childhood ADHD: Interactions with offspring monoamine oxidase A (MAO-A) genotype. Journal of Abnormal Child Psychology, 40, 165-175. Doi: 10.1007/s10802-011-9553-z [PubMed: 21826446]

Li JJ, \& Lee SS. (2013). Interaction of dopamine transporter gene and observed parenting behaviors on attention-deficit/hyperactivity disorder: a structural equation modeling approach. Journal of Clinical Child \& Adolescent Psychology, 42, 174-186. Doi: 10.1080/15374416.2012.736355 [PubMed: 23153115]

Li JJ. (2017). Assessing the interplay between multigenic and environmental influences on adolescent to adult pathways of antisocial behaviors. Development and Psychopathology, 29, 1947-1967. Doi: 10.1017/S0954579417001511 [PubMed: 29162195]

Long JS, \& Freese J. (2006). Regression models for categorical dependent variables using Stata. College Station: Stata Press, 2006

Luman M, Oosterlaan J, \& Sergeant JA. (2005). The impact of reinforcement contingencies on AD/HD: A review and theoretical appraisal. Clinical Psychology Review, 25, 183-213. Doi: 10.1016/j.cpr.2004.11.001 [PubMed: 15642646]

Luman M, Tripp G, \& Scheres A. (2010). Identifying the neurobiology of altered reinforcement sensitivity in ADHD: A review and research agenda. Neuroscience \& Biobehavioral Reviews, 34, 744-754. Doi: 10.1016/j.neubiorev.2009.11.021 [PubMed: 19944715]

Luman M, Sergeant JA, Knol DL, \& Oosterlaan J. (2010). Impaired decision making in oppositional defiant disorder related to altered psychophysiological responses to reinforcement. Biological Psychiatry, 68, 337-344. Doi: 10.1016/j.biopsych.2009.12.037 [PubMed: 20359697]

Luman M, van Meel CS, Oosterlaan J, \& Geurts HM. (2012). Reward and punishment sensitivity in children with ADHD: validating the sensitivity to punishment and reward responsivity questionnaire for children (SPSRQ-C). Journal of Abnormal Child Psychology, 40, 145-157. Doi: 10.1007/s10802-011-9547-x [PubMed: 21789519]

Ma I, van Duijvenvoorde A, \& Scheres A. (2016). The interaction between reinforcement and inhibitory control in ADHD: A review and research guidelines. Clinical Psychology Review, 44, 94-111. Doi: 10.1016/j.cpr.2016.01.001 [PubMed: 26802874]

Masten AS, \& Coatsworth JD. (1998). The development of competence in favorable and unfavorable environments: Lessons from research on successful children. American Psychologist, 53, 205-220. Doi: 10.1037/0003-066X.53.2.205 [PubMed: 9491748] 
McLeod BD, Wood JJ, \& Weisz JR. (2007). Examining the association between parenting and childhood anxiety: A meta-analysis. Clinical Psychology Review, 27, 155-172. Doi: 10.1016/ j.cpr.2006.09.002 [PubMed: 17112647]

Newman JP, \& Wallace JF. (1993). Diverse pathways to deficient self-regulation: Implications for disinhibitory psychopathology in children. Clinical Psychology Review, 13, 699-720. Doi: $10.1016 / \mathrm{S} 0272-7358(05) 80002-9$

NICHQ (2002). Vanderbilt Assessment Scales (1st Ed). American Academy of Pediatrics Retrieved from http://www.nichq.org/childrens-health/adhd/resources/vanderbilt-assessment-scales.

Nigg JT, Goldsmith HH, \& Sachek J. (2004). Temperament and attention deficit hyperactivity disorder: The development of a multiple pathway model. Journal of Clinical Child and Adolescent Psychology, 33, 42-53. Doi: 10.1207/S15374424JCCP3301_5 [PubMed: 15028540]

Nigg JT, \& Casey BJ. (2005). An integrative theory of attention-deficit/hyperactivity disorder based on the cognitive and affective neurosciences. Development and Psychopathology, 17, 785-806. Doi: 10.1017/S0954579405050376 [PubMed: 16262992]

Pettit GS, Bates JE, \& Dodge KA. (1997). Supportive parenting, Ecological Context, and Children's Adjustment: A Seven-Year Longitudinal Study. Child Development, 68, 908-923. Doi: 10.1111/ j.1467-8624.1997.tb01970.x [PubMed: 29106716]

Plichta MM, \& Scheres A. (2014). Ventral-striatal responsiveness during reward anticipation in ADHD and its relation to trait impulsivity in the healthy population: A meta-analytic review of the fMRI literature. Neuroscience \& Biobehavioral Reviews, 38, 125-134. Doi: 10.1016/ j.neubiorev.2013.07.012 [PubMed: 23928090]

Quay HC. (1988). The behavioral reward and inhibition system in childhood behavior disorder. In Bloomingdale LM. (Ed.), Attention deficit disorder, Vol. 3. New research in attention, treatment, and psychopharmacology (pp. 176-186). Elmsford, NY: Pergamon Press.

Richards JS, Vásquez AA, Rommelse NN, Oosterlaan J, Hoekstra PJ, Franke B, .. \& Buitelaar JK. (2014). A follow-up study of maternal expressed emotion toward children with attention-deficit/ hyperactivity disorder (ADHD): Relation with severity and persistence of ADHD and comorbidity. Journal of the American Academy of Child \& Adolescent Psychiatry, 53, 311-319. Doi: 10.1016/ j.jaac.2013.11.011 [PubMed: 24565358]

Rubia K, Halari R, Cubillo A, Mohammad AM, Brammer M, \& Taylor E. (2009). Methylphenidate normalizes activation and functional connectivity deficits in attention and motivation networks in medication-naive children with ADHD during a rewarded continuous performance task. Neuropharmacology, 57, 640-652. Doi: 10.1016/j.neuropharm.2009.08.013 [PubMed: 19715709]

Sanson A, \& Prior M. (1999). Temperament and behavioral precursors to oppositional defiant disorder and conduct disorder. In Handbook of disruptive behavior disorders (pp. 397-417). Springer US.

Scheres A, Milham MP, Knutson B, \& Castellanos FX. (2007). Ventral striatal hyporesponsiveness during reward anticipation in attention-deficit/hyperactivity disorder. Biological Psychiatry, 61, 720-724. Doi: 10.1016/j.biopsych.2006.04.042 [PubMed: 16950228]

Shaffer D, Fisher P, Lucas CP, Dulcan MK, \& Schwab-Stone ME. (2000). NIMH Diagnostic Interview Schedule for Children Version IV (NIMH DISC-IV): description, differences from previous versions, and reliability of some common diagnoses. Journal of the American Academy of Child \& Adolescent Psychiatry, 39, 28-38. Doi: 10.1097/00004583-200001000-00014 [PubMed: 10638065]

Shelton KK, Frick PJ, \& Wootton J. (1996). Assessment of parenting practices in families of elementary school-age children. Journal of Clinical Child Psychology, 25, 317-329. Doi: 10.1207/ s15374424jccp2503_8

Slagt M, Dubas JS, Deković M, \& van Aken MAG. (2016). Differences in sensitivity to parenting depending on child temperament: A meta-analysis. Psychological Bulletin, 142, 1068-1110. Doi: 10.1037/bul0000061 [PubMed: 27513919]

Sonuga-Barke EJ, Sergeant JA, Nigg J, \& Willcutt E. (2008). Executive dysfunction and delay aversion in attention deficit hyperactivity disorder: nosologic and diagnostic implications. Child and Adolescent Psychiatric Clinics of North America, 17, 367-384. Doi: https://doiorg.ezproxy.library.wisc.edu/10.1016/j.chc.2007.11.008 [PubMed: 18295151] 
Sonuga-Barke EJ, \& Halperin JM. (2010). Developmental phenotypes and causal pathways in attention deficit/hyperactivity disorder: potential targets for early intervention? Journal of Child Psychology and Psychiatry, 51, 368-389. Doi: 10.1111/j.1469-7610.2009.02195.x [PubMed: 20015192]

StataCorp. 2015 Stata 14 Base Reference Manual. College Station, TX: Stata Press.

Torrubia R, Avila C, Moltó J, \& Caseras X. (2001). The Sensitivity to Punishment and Sensitivity to Reward Questionnaire (SPSRQ) as a measure of Gray's anxiety and impulsivity dimensions. Personality and Individual Differences, 31, 837-862. Doi: 10.1016/S0191-8869(00)00183-5

Tripp G, \& Alsop B. (2001). Sensitivity to reward delay in children with attention deficit hyperactivity disorder (ADHD). The Journal of Child Psychology and Psychiatry and Allied Disciplines, 42, 691-698. Doi: 10.1111/1469-7610.00764

Tripp G, \& Wickens JR. (2008). Research review: dopamine transfer deficit: a neurobiological theory of altered reinforcement mechanisms in ADHD. Journal of Child Psychology and Psychiatry, 49, 691-704. Doi: 10.1111/j.1469-7610.2007.01851.x [PubMed: 18081766]

van Meel CS, Oosterlaan J, Heslenfeld DJ, \& Sergeant JA. (2005). Telling good from bad news: ADHD differentially affects processing of positive and negative feedback during guessing. Neuropsychologia, 43, 1946-1954. Doi: 10.1016/j.neuropsychologia.2005.03.018 [PubMed: 15878183]

Veroude K, von Rhein D, Chauvin RJM, van Dongen EV, Mennes MJJ, Franke B. ... \& Buitelaar JK. (2016). The link between callous-unemotional traits and neural mechanisms of reward processing: An fMRI study. Psychiatry Research: Neuroimaging, 255, 75-80. Doi: 10.1016/ j.pscychresns.2016.08.005 [PubMed: 27564545]

Willcutt EG. (2012). The prevalence of DSM-IV attention-deficit/hyperactivity disorder: a metaanalytic review. Neurotherapeutics, 9, 490-499. Doi: 10.1007/s13311-012-0135-8 [PubMed: 22976615] 


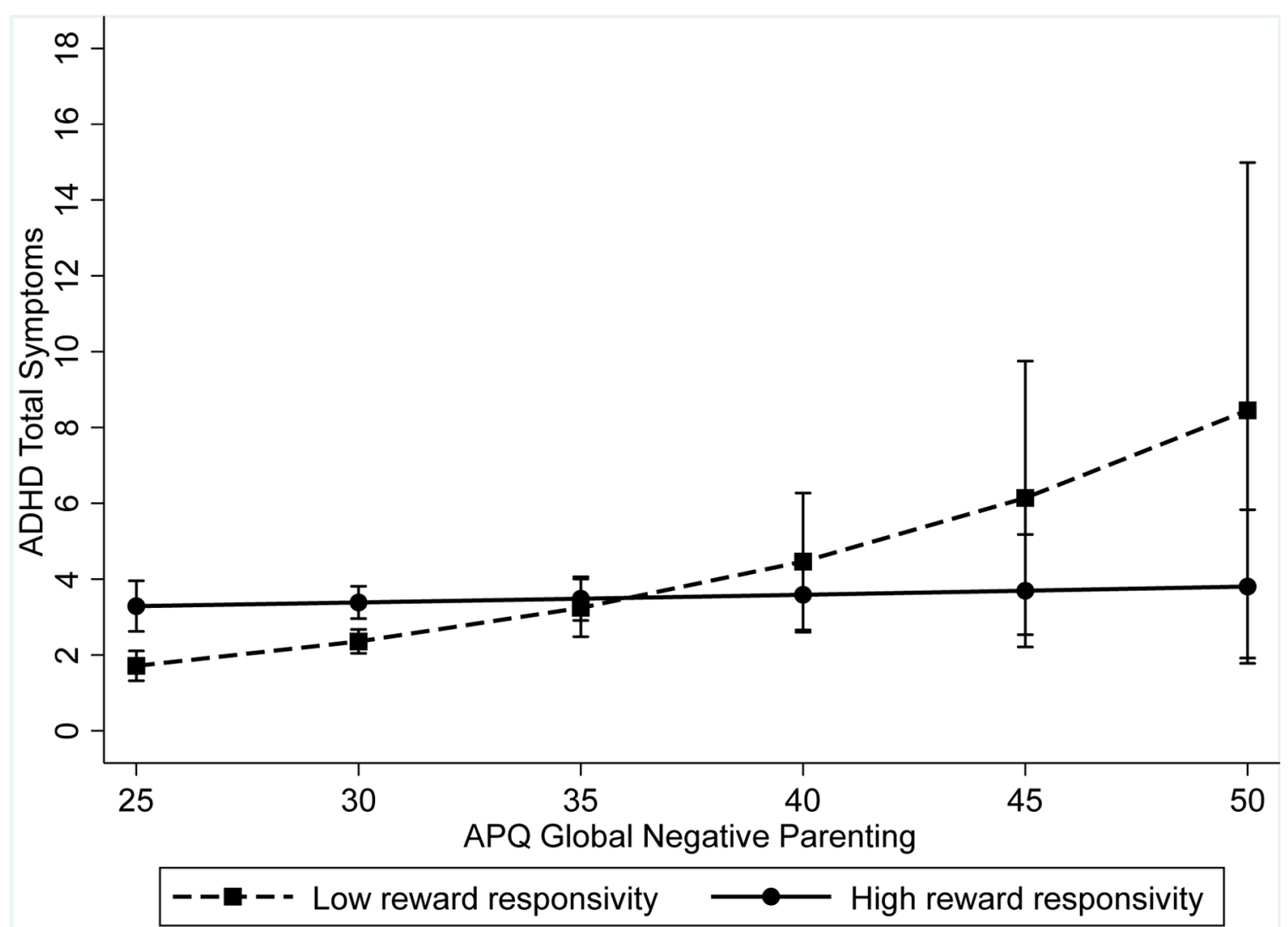

Figure 1.

Interaction between global negative parenting with child reward responsivity on ADHD total symptoms

Note. Error bars are 95\% confidence intervals. Low reward responsivity is an SPSRQ-C score $<25$ (below the median); High reward responsivity is an SPSRQ-C score of $>=25$ (above the median); High APQ global negative parenting = more negative parenting behaviors; Low APQ global negative parenting = less negative parenting behaviors. 


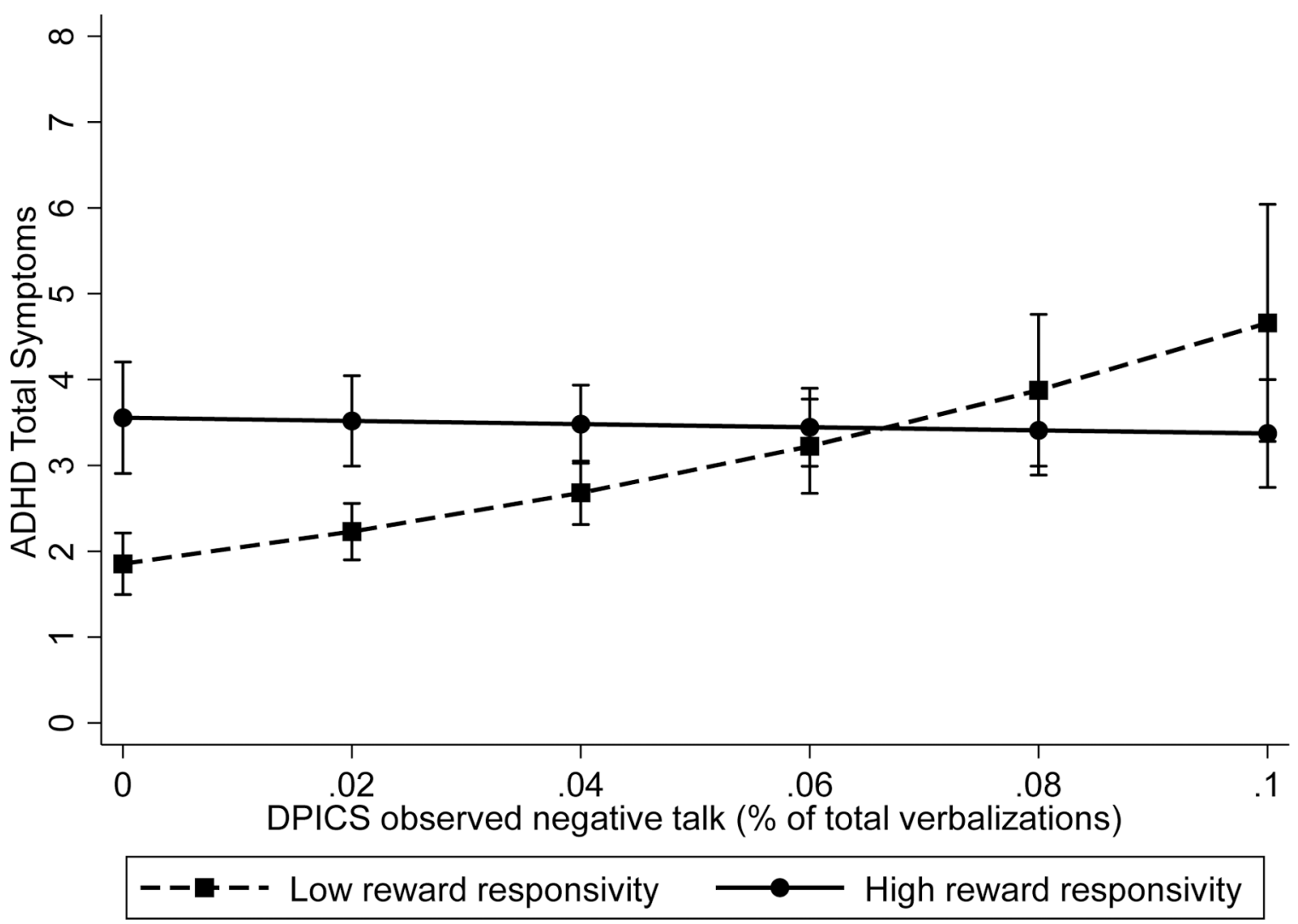

Figure 2.

Interaction between observed negative parenting with child reward responsivity on ADHD symptoms

Note. Error bars are 95\% confidence intervals; Low reward responsivity is an SPSRQ-C score $<25$ (below the median); High reward responsivity is an SPSRQ-C score of $>=25$ (above the median); High DPICS observed negative talk $\%=$ more negative talk; Low DPICS observed negative talk \% = less negative talk. 


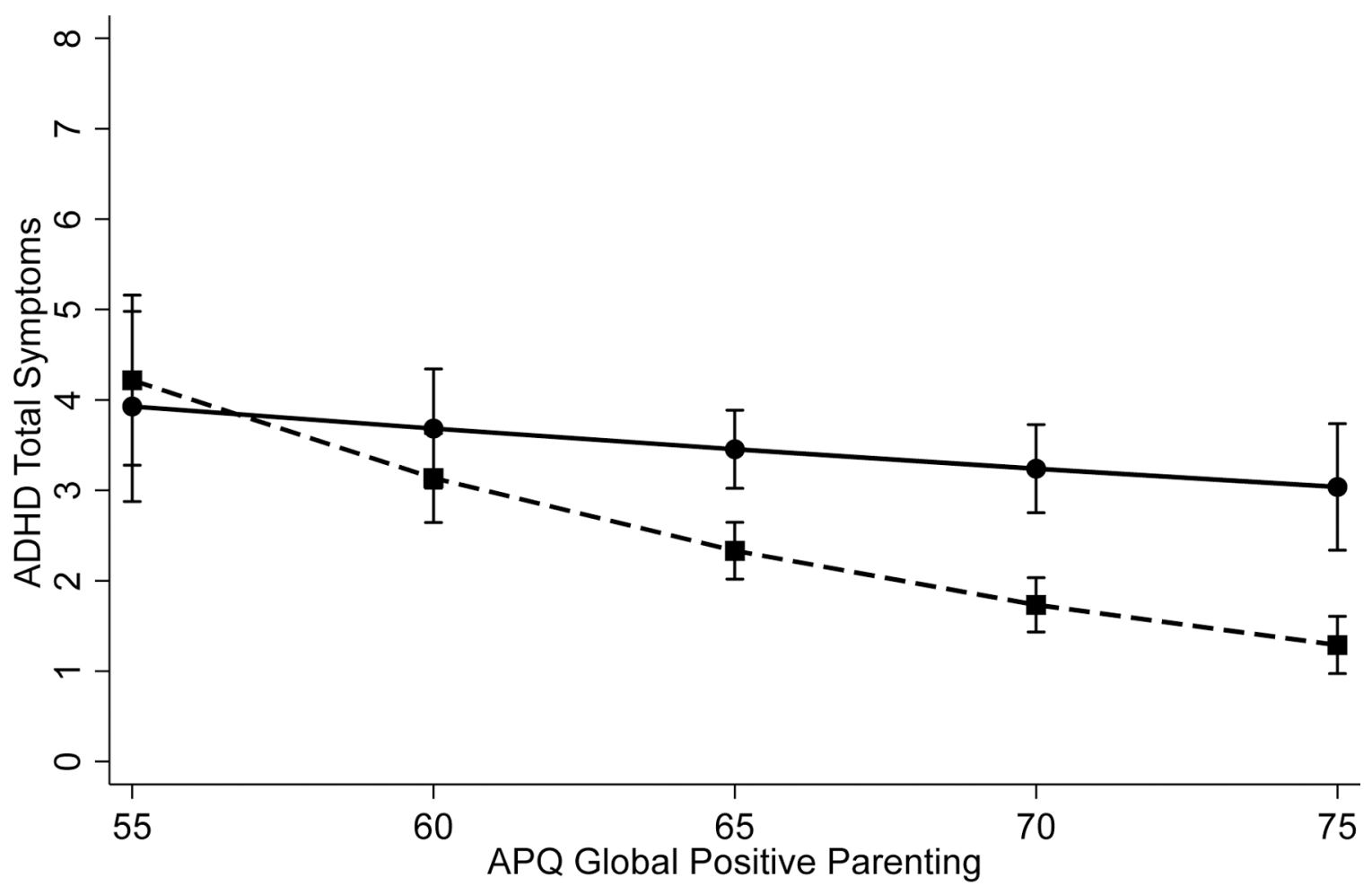

\section{- - - - Low reward responsivity $\longrightarrow$ High reward responsivity}

Figure 3.

Interaction between global positive parenting with child reward responsivity on ADHD total symptoms

Note. Error bars are 95\% confidence intervals. Low reward responsivity is an SPSRQ-C score $<25$ (below the median); High reward responsivity is an SPSRQ-C score of $>=25$ (above the median); High global positive parenting = more positive parenting behaviors, Low global positive parenting $=$ less positive parenting behaviors. 


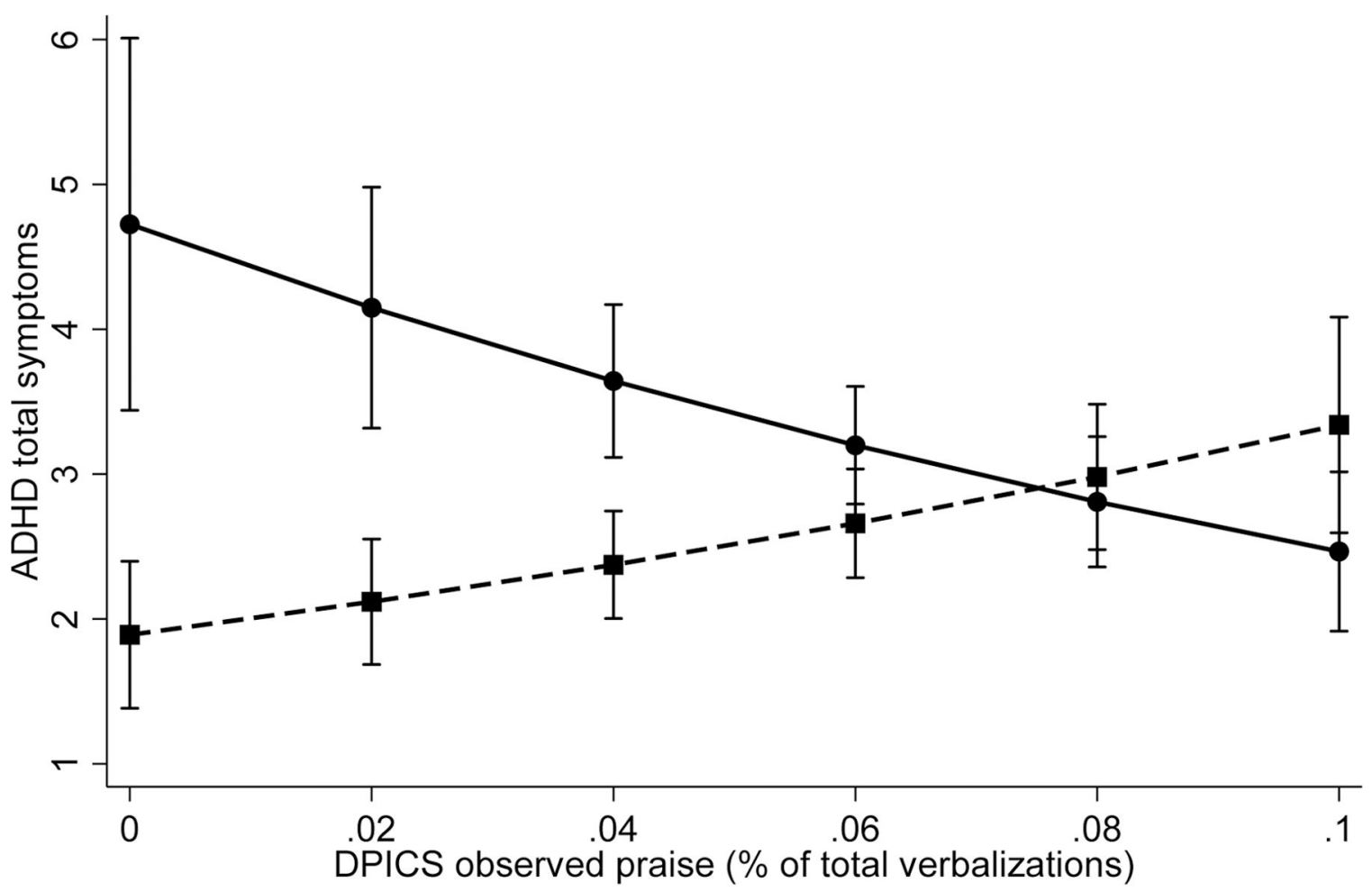

- - - - - Low sensitivity to punishment $\longrightarrow \longrightarrow$ High sensitivity to punishment

Figure 4.

Interaction between observed positive parenting with child reward responsivity on ADHD total symptoms.

Note. Error bars are 95\% confidence intervals. Low sensitivity to punishment is an SPSRQ$\mathrm{C}$ score $<34$ (below the median); High sensitivity to punishment is an SPSRQ-C score of $>=34$ (above the median); High DPICS observed praise $\%=$ more praise; Low DPICS observed praise $\%=$ less praise. 

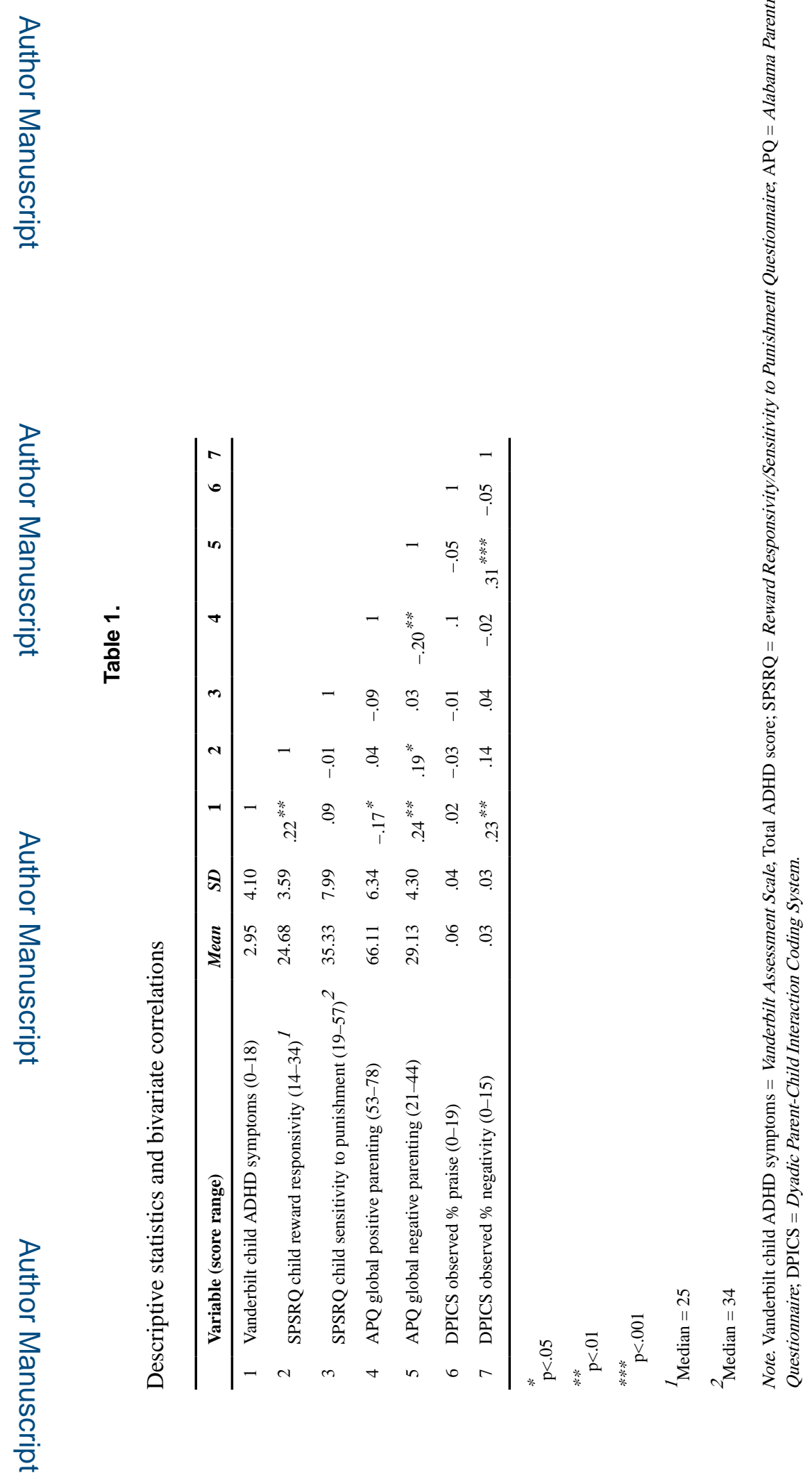

J Abnorm Child Psychol. Author manuscript; available in PMC 2020 April 30. 


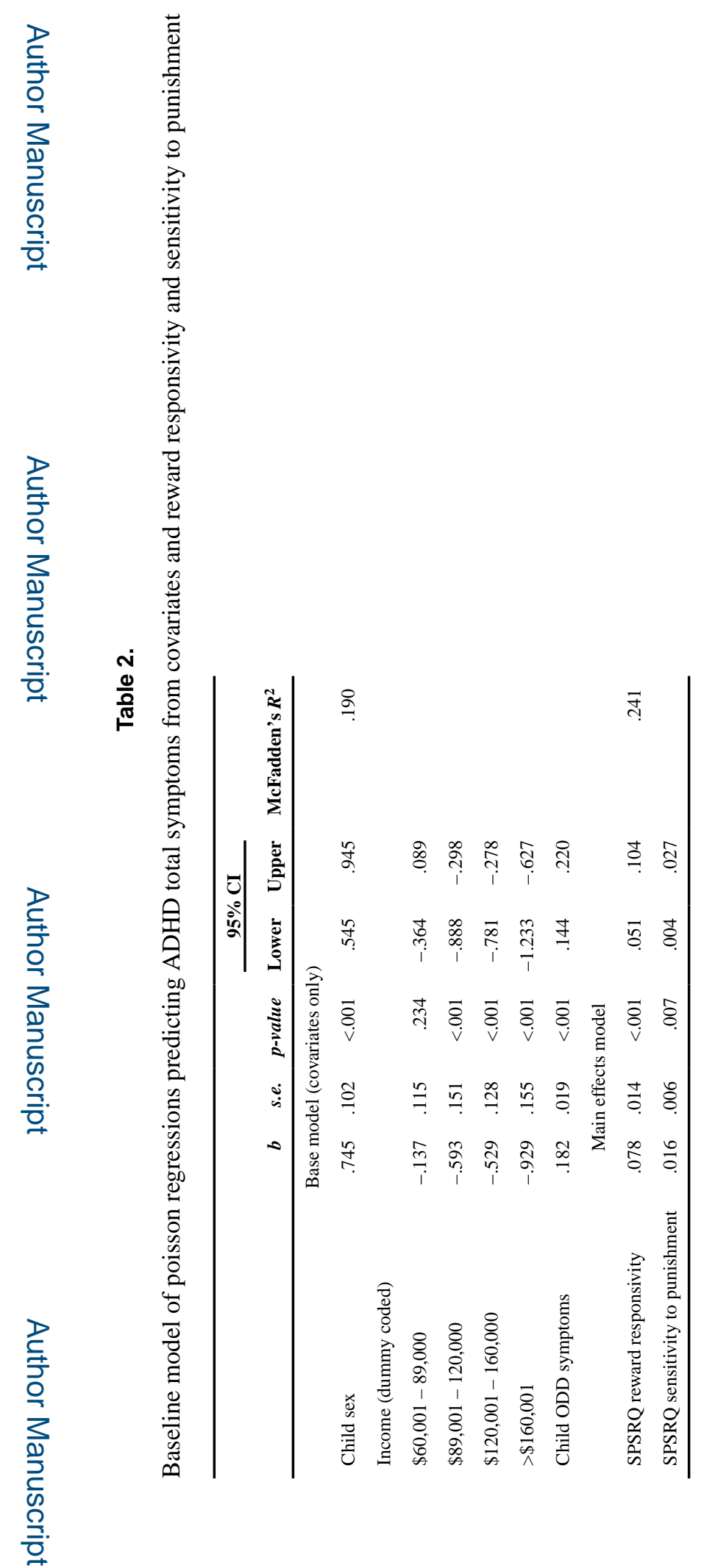

J Abnorm Child Psychol. Author manuscript; available in PMC 2020 April 30. 


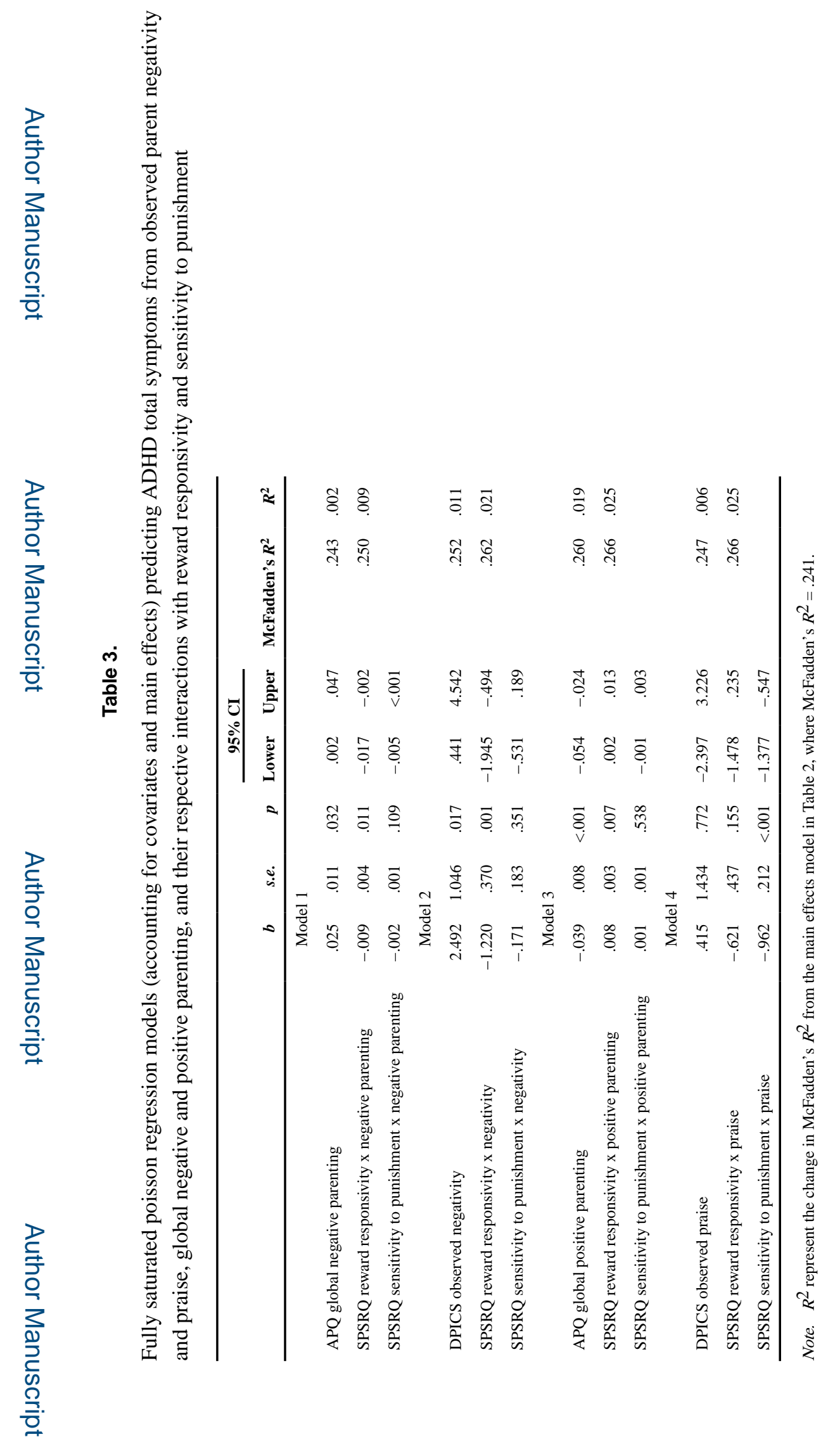

J Abnorm Child Psychol. Author manuscript; available in PMC 2020 April 30. 